\title{
HER2/NEU PROTEIN EXPRESSION IN COLORECTAL CANCER
}

\author{
Nimmy Andrews ${ }^{1}$, Letha $V^{2}$, Sankar $S^{3}$
}

${ }^{1}$ Resident, Department of Pathology, Government Medical College, Kottayam, Kerala, India.

${ }^{2}$ Additional Professor, Department of Pathology, Government Medical College, Kottayam, Kerala, India.

3 Professor and HOD, Department of Pathology, Government Medical College, Kottayam, Kerala, India.

\begin{abstract}
\section{BACKGROUND}

Conflicting data exists about the prevalence of HER2/neu over expression in colorectal cancer ranging from $7 \%$ to $83 \%$. $^{1}$ Here we are trying to clarify the extent of expression of HER2/neu in Colorectal cancer in our population. In contrast to breast cancer, in colorectal cancer, cytoplasmic HER2 could be associated with good prognosis. HER2 targeted drugs can restrain invasion and metastasis of colorectal cancer in which HER2 is overexpressed.

Aims and Objectives- To study the rate and pattern of HER2/neu status in surgically resected tissue in colorectal carcinoma. To describe the expression of HER2/neu in relation to age, sex, TNM stage, grade and primary location of colorectal carcinoma.

Setting- Department of Pathology, Government Medical College, Kottayam.

Design- Descriptive study, Cross sectional study.
\end{abstract}

\section{MATERIALS AND METHODS}

Descriptive study was conducted in 50 resected specimens of colorectal cancer received in department of Pathology, Government Medical College, Kottayam, during study period of 18 months (April 2017 to September 2018).

Analysis-SPSS software.

\section{RESULTS}

Mean age of the present study was 61.8. Majority of patients belong to 60-69 years age group (46\%). Rectosigmoid region was most prone for CRC in this study constituting 21 cases (42\%). $74 \%$ cases were well differentiated type, but no cases of poorly differentiated type were seen in this study. HER2 was positive in $84 \%$ cases which was comparable with the study done by Asma Shabbir et al. 36\% showed weak positivity, $40 \%$ showed moderate positivity and $8 \%$ showed strong positivity. 50\% cases showed Score 3+. HER2 positivity showed significant association with location of malignancy- highest in rectosigmoid region (42\%) and lowest in transverse colon (8\%). Other clinicopathologic variables showed no significant association with HER2 positivity, intensity, pattern and scoring.

\section{CONCLUSION}

The present study was done to describe the rate and pattern of positivity of HER2 in colorectal carcinoma specimens and to describe the relation with various clinicopathologic variables. HER2 was positive in $84 \%$ cases in this study. Association between HER2 positivity and location of malignancy is found to be significant with a p value of 0.01 . Highest was found in Rectosigmoid region and lowest was found in transverse colon, $42 \%$ and $8 \%$ respectively.

\section{KEY WORDS}

Colorectal Cancer, HER2, Resected Specimen.

HOW TO CITE THIS ARTICLE: Andrews N, Letha V, Sankar S. HER2/NEU protein expression in colorectal cancer. J. Evolution Med. Dent. Sci. 2019;8(06): 341-345, DOI: 10.14260/jemds/2019/75

\section{BACKGROUND}

Colorectal carcinoma accounts for about $10 \%$ of new cancer diagnoses and $11 \%$ of deaths related to cancer. It is the fourth most common malignancy worldwide, with $\sim 10$ lakh new cases and 5 lakh deaths recorded each year. ${ }^{2}$ Current estimates suggest that more than half of the patients with Colorectal cancer will either have liver metastases at presentation or subsequently develop metastasis. Among patients who undergo curative resection for Colon cancer, $10-20 \%$ will develop pulmonary metastasis and $10 \%$ of these patients will have isolated pulmonary lesions. ${ }^{3}$

'Financial or Other Competing Interest': None.

Submission 19-12-2018, Peer Review 24-01-2019,

Acceptance 31-01-2019, Published 11-02-2019.

Corresponding Author:

Nimmy Andrews,

Vadakkekollamparambil House,

Thalayolaparambu, P. O.,

Kottayam-686605, Kerala, India.

E-mail: nimmyandrews121@gmail.com

DOI: $10.14260 /$ jemds $/ 2019 / 75$

\section{(c) (i) $\$$}

Despite advances in surgery and adjuvant therapy, colorectal cancer remains one of the leading causes of cancerrelated deaths worldwide. Further improvements in understanding tumour biology and identifying oncogenic agents have led to the development of new therapeutic targets. Therefore, identification of biological markers for targeted therapy continues to be a high priority in human cancer treatment. Human Epidermal Growth Factor (HER2/neu) has strong therapeutic implications in certain cancers like breast cancer and gastric cancer. ${ }^{4}$ Literature on its frequency in colorectal cancer is scarce. Conflicting data exist about the prevalence of HER2/neu overexpression in colorectal cancer ranging from $0 \%$ to $83 \%$. In contrast to breast cancer, there is evidence that in colorectal cancer cytoplasmic HER2 could be associated with good prognosis. Also HER2 targeted drugs can restrain invasion and metastasis of Colorectal cancer in which HER2 is overexpressed. 
MATERIALS AND METHODS

Study Design

Descriptive study.

\section{Study Setting}

Department of Pathology, Government Medical College, Kottayam.

\section{Study Period}

April 2017 to September 2018

\section{Study Population}

50 cases of colorectal cancer specimens which are received in the Department of Pathology, Government medical college, Kottayam during my study period from April 2017 to September2018

\section{Sample Size}

Sample size $(\mathrm{n})=4 \mathrm{pq} / \mathrm{d}^{2}$

According to study done by Asma shabbir et $\mathrm{al}^{5}$ we got

P- Prevalence of Her-2 positivity in colorectal cancer in previous study $=78.9 \%$

Fixing Relative Precision (d) as $15 \%$ of $\mathrm{P},=15 \times 78.9 / 100=11.8$ $\mathrm{q}=100-\mathrm{p}=100-78.9=21.1$

Sample size $(\mathrm{n})$ is calculated as

$4 \mathrm{pq} / \mathrm{d}^{2}$

$\left.(4 \times 78.9 \times 21.1) / 11.8^{2}\right)=50$.

\section{Inclusion Criteria}

All cases of adenocarcinoma of Colon and rectum in surgically resected specimens

\section{Exclusion Criteria}

Small biopsies of colon and rectum with adenocarcinoma are excluded.

\section{Study Tool}

1. Clinical proforma.

2. Clean dry microscopic slide.

3. Haematoxylin and eosin stain.

4. HER2//Erb2 (EP3).

5. Microscope.

6. Formalin fixed paraffin embedded specimen.

\section{Study Procedure}

All specimens are received in formalin. These are processed, paraffin embedded, thin (5micronmeter) sections are taken and stained by Haematoxylin and Eosin and immunohistochemistry for HER2/neu. Immunohistochemical staining should be conducted as follows:

\footnotetext{
Standard Operating Procedure (Immunohistochemistry) Principle

Formalin fixation plus tissue processing in paraffin as well as even dehydration with ethanol can mask many antigenic sites and hinder antibody binding. Immunohistochemistry involves exposure of these antigenic sites by treating thin paraffin sections to high heat bathed in various solutions with controlled $\mathrm{pH}$ with the help of a pressure cooker/antigen retriever. The final result is interpreted by the development of brown Colour in tissue sections.
}

Materials/Microtome APES Coated Glass Slides (or

Positively Charged Slides)

- Xylene.

- Ethanol Peroxide.

- Distilled water.

- Antigen retriever.

- 700-900 Watt Pressure Cooker.

- Slide racks.

- Glass dishes for buffers.

- Plastic, microwaveable rack containers.

- Humid/moisture chamber.

- Counterstain (Haematoxylin).

- Sodium Phosphate, Dibasic-500gms.

- Sodium Dihydrogen Phosphate, Monohydrate-500 gms.

- Mounting medium-DPX (Distrene Dibutyl phthalate Xylene).

- $\quad$ Cover slips (22x22mms).

\section{Buffers}

1. Tris Buffer Saline (TBS): pH 7.6(IHC Wash Buffer)

- Tris-0.605 g.

- NaCl-8 gms.

- $\quad 1 \mathrm{~N} \mathrm{HCl}-4.4 \mathrm{ml} \mathrm{pH-7.6.}$

- Distilled water-1 Litre.

Mix to dissolve. Adjust pH to 7.6 with $1 \mathrm{~N} \mathrm{HCl}$ and then store this solution at room temperature for 3 months or at $4 \mathrm{C}$ for longer storage.

2. Citrate Buffer (Antigen Retrieval Buffer) pH6.0

- Tri-sodium citrate (Dihydrate)-2.94 g.

- Distilled water- $1000 \mathrm{ml}$.

- 1 Normal HCl-5ml.

Mix to dissolve. Adjust $\mathrm{pH}$ to 6.0 with $1 \mathrm{~N} \mathrm{HCl}$ and then store this solution at room temperature for 3 months or at $4 \mathrm{C}$ for longer storage.

\section{Tris EDTA buffer (Antigen retrieval buffer)pH9.0}

- Tris Base-1.21 g.

- $\quad$ EDTA (Ethylene Diamine Tetra Acetic acid)-0.37 g.

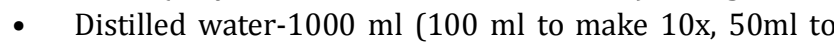
make 20x).

- $\quad$ Mix to dissolve. Adjust the pH to 9.0 with $1 \mathrm{~N} \mathrm{NaOH,} \mathrm{mix}$ well.

- $\quad$ Store this solution at room temperature for 3 months or at $4^{\circ} \mathrm{C}$ for longer storage.

\section{Procedure}

\section{(a). Preparation of Paraffin Slides}

1. Prepare sections between 3-4micrometer thickness on Poly-L-Lysine coated slides or silanized slides to keep the samples from detaching, especially during antigen retrieval approaches. Mark the sections carefully for antigens to be detected and keep the slides in a slide rack

2. Incubate the slides overnight at $60^{\circ} \mathrm{C}$

\section{OR}

3. After air dry, bake the slides at $600 \mathrm{C}$ for $1 \mathrm{hr}$ in Hot air oven.

4. Dip slides in xylene (three times) for 10 minutes each to remove the paraffin. 
5. Rehydrate the tissues by dipping the slides in absolute ethanol(100\%), then in $90 \%$ ethanol(2changes, 5 minutes each)

6. Keep in running tap water for 10 minute.

\section{(b). Antigen Retrieval}

Place the slide rack in $300-400 \mathrm{ml}$ of citrate buffer or Tris EDTA buffer for 3 minutes at room temperature.

Place rest of the buffer and the slide rack in the pressure cooker or antigen retriever (Depending on the method used). Assemble the top and lid of the pressure cooker and lock into position; place the cooker onto a hot plate and cook for 10 minutes or for 40 minutes at high power in antigen retriever. When the cooking time is completed, remove the pressure cooker immediately and keep under running tap water. When the steam is completely dissipated, open the lid and very carefully remove the slides. Place slides in wash buffer for 5 minutes.

\section{(c). Detection}

1. Cover sections with Peroxide block for 10 minutes. Wash sections in TBS for $2 \times 5$ minutes.

2. Incubate with Power Block for 10 minutes.

3. Incubate with Primary antibody for 30 minutes. Wash in TBS for $2 \times 5$ minutes.

4. Incubate with super enhancer for 20 minutes. Wash in TBS for $2 \times 5$ minutes.

5. Incubate with SS Label for 30 minutes. Wash in TBS for 2x5 minutes.

6. Develop peroxidase activity with DAB (3, 3'-Di Amino Benzidine) working solution for 5.minutes. (Prepare DAB Working Solution by adding 50 microliters of DAB Chromogen to $1 \mathrm{ml}$ of DAB buffer). Rinse slides in running water.

7. Counterstain with Haematoxylin. Rinse slides in water for 5 minutes for blueing.

8. Dehydrate, clear and mount sections with DPX.

\section{Statistics}

The Data was entered in Microsoft Excel and further Statistical Analysis was done using SPSS Software

1. Mean and frequency of-

- Age.

- Sex.

- Anatomical location.

- Grade.

- HER2 positivity.

- Intensity of HER2 positivity.

- Score of HER2 positivity.

- Pattern of HER2 positivity.

2. Relation between HER2/neu protein expression and other clinic pathologic variables were studied using chisquare testing and $\mathrm{p}$ value was calculated accordingly.

\section{RESULTS}

Descriptive study of frequency of HER2/neu positivity in 50 cases of CRC in resected specimens was done in department of Pathology, GOVT Medical College Kottayam during the study period of 18 months. Mean age of the present study was 61.8 , minimum age was 26 years and maximum was 85.Majority of patients belong to 60-69age group (46\%) Sex preponderance was equal in our study?. Rectosigmoid region was most prone for CRC in this study constituting 21 cases (42\%).74\% cases were well differentiated type and $26 \%$ were moderately differentiated, but no cases of poorly differentiated type were received in the study? period. Lymphovascular emboli was present in $15 \%$ cases in the present study. HER2/neu was positive in $84 \%$ cases which was comparable with the study of Asma Shabbir et al. 36\% showed weak positivity, $40 \%$ showed moderate positivity and $8 \%$ showed strong positivity. $50 \%$ cases showed score $3+$, $24 \%$ showed score $2+$ and $10 \%$ showed score $1+$ for HER2/neu positivity. HER2/neu positivity showed significant association with location of malignancy-highest in Rectosigmoid region (42\%) and lowest in Transverse Colon (8\%)Other clinicopathologic variables showed no significant association with HER2/neu positivity, intensity, pattern and scoring.

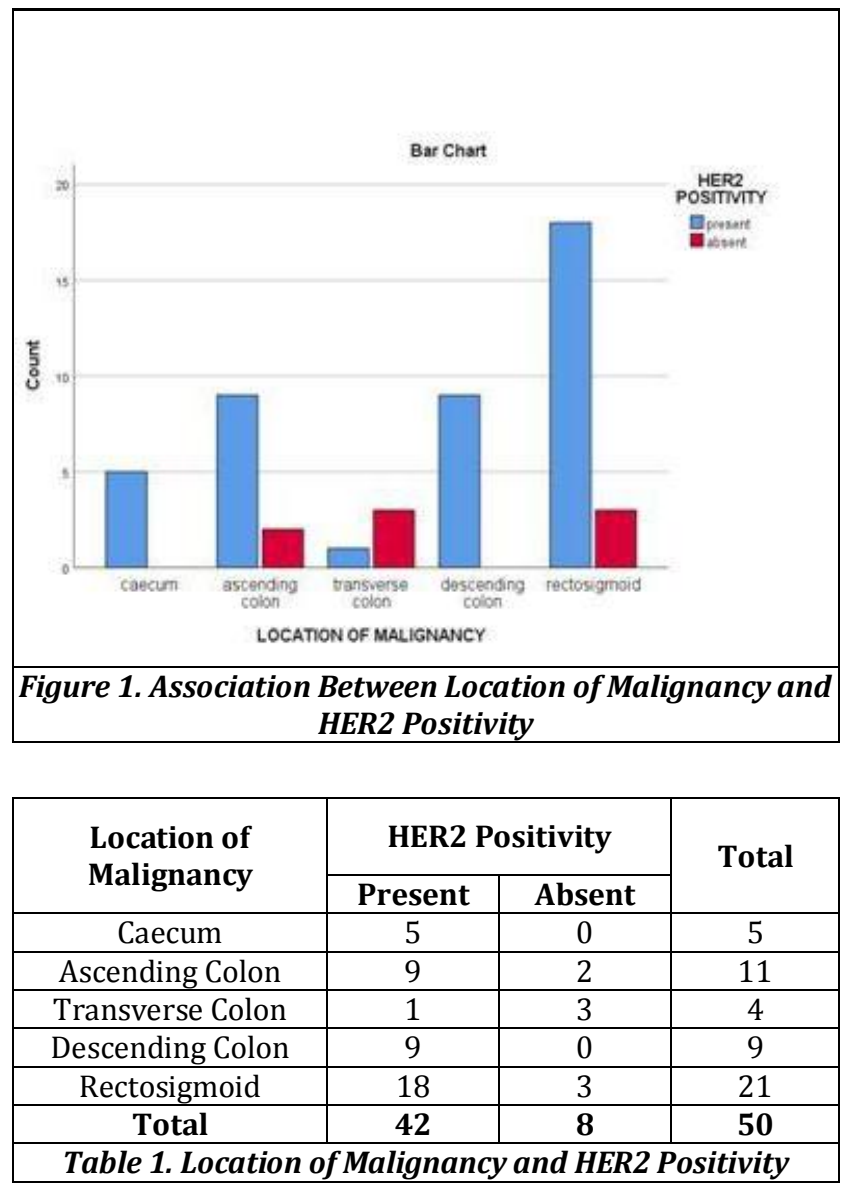




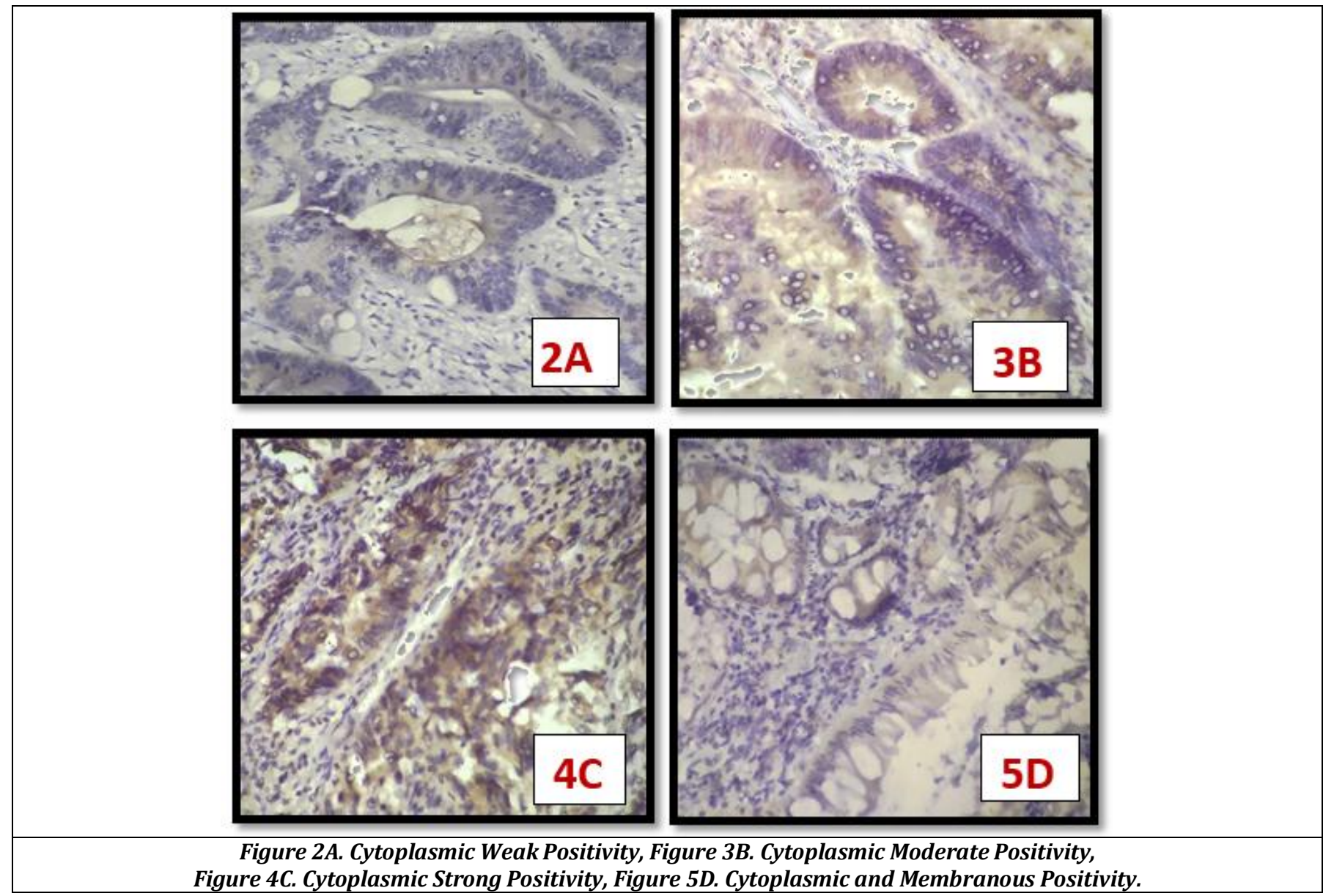

\begin{tabular}{|c|c|}
\hline & HER2 \\
\hline Present Study & $84 \%$ \\
\hline Asma Shabbir et al & $78.9 \%$ \\
\hline Seo et al & $65 \%$ \\
\hline Suma et al & \\
\hline
\end{tabular}

Table $2.84 \%$ cases are variably positive for HER2 in the present study. This finding is comparable with study of Asma Shabbir et al. 78.9\% cases were positive for HER2 in their study

\begin{tabular}{|c|c|c|c|}
\hline & Weak & Moderate & Strong \\
\hline Present Study & $36 \%$ & $40 \%$ & $8 \%$ \\
\hline $\begin{array}{c}\text { Asma Shabbir et } \\
\text { al }\end{array}$ & $25.3 \%$ & $46.6 \%$ & $28 \%$ \\
\hline Suma et al & $20.00 \%$ & $12.00 \%$ & $12.00 \%$ \\
\hline
\end{tabular}

Table 3. Comparing the intensity of HER2 positivity, our study showed $40 \%$ moderately positive cases, $36 \%$ are weakly positive and $8 \%$ are strongly positive whereas study of Asma Shabbir et al also showed more moderately positive cases

\begin{tabular}{|c|c|c|c|}
\hline & Cytoplasmic & Membranous & Both \\
\hline Present Study & $54 \%$ & $0 \%$ & $30 \%$ \\
\hline Asma Shabbir et al & $48 \%$ & $26.6 \%$ & $25.3 \%$ \\
\hline Seo et al & $57.5 \%$ & $0 \%$ & $7.5 \%$ \\
\hline
\end{tabular}

Table 4. On comparing the pattern of HER2 staining, the present study showed 54\% cytoplasmic staining and 30\% both cytoplasmic and membranous staining. No cases of membranous staining were seen in our study. In the study of Asma Shabbir et al, $26.6 \%$ showed membranous HER2/neu expression, $48 \%$ cases showed cytoplasmic expression and $25.3 \%$ cases showed membranous + cytoplasmic expression

\begin{tabular}{|c|c|c|c|}
\hline & $\mathbf{1 +}$ & $\mathbf{2 +}$ & $\mathbf{3 +}$ \\
\hline Present Study & $10 \%$ & $24 \%$ & $50 \%$ \\
\hline $\begin{array}{c}\text { Asma Shabbir et } \\
\text { al }\end{array}$ & $30.6 \%$ & $24 \%$ & $45.3 \%$ \\
\hline
\end{tabular}

Table 5. According to the present study, HER2 was negative in $16 \%$ cases, and score of $3+$ was seen in $50 \%$ cases. In the study of Asma Shabbir et al, $21.1 \%$ were negative for HER2 and score of $3+$ was found in $45.3 \%$ cases

\section{DISCUSSION}

HER2 is a member of the epidermal growth factor family and is over expressed in malignancies of breast, ovarian, gastric, Colorectal, pancreatic and endometrial cancers 4 . HER2/neu expression can be either membranous or cytoplasmic with different clinical implications in different cancers. For example, cytoplasmic HER2/neu in breast cancer does occur but it is considered irrelevant because the monoclonal antibodies approved for its treatment, targets only membranous forms. But HER2/neu expression is membranous as well as cytoplasmic in colorectal adenocarcinoma with cytoplasmic expression favouring survival prognosis.

The present study was conducted in 50 cases of resected specimens of colorectal carcinoma in department of pathology, Govt. Medical College, Kottayam during April 2017 to September 2018. Immunostaining for HER2/neu was done in all cases and it is interpreted. 


\section{CONCLUSION}

HER2/neu was positive in $84 \%$ cases in this study.

Association between HER2/neu positivity and location of colorectal carcinoma is found to be significant with a $\mathrm{p}$ value of $0.01(<0.05)$. Highest positivity was found in rectosigmoid region and lowest was found in transverse colon, $42 \%$ and $8 \%$ respectively.

\section{ACKNOWLEDGEMENT}

I express my sincere gratitude to Dr. Sankar S., Professor and Head of Department of Pathology, Dr. Letha V, Additional Professor, Department of Pathology, Government Medical College, Kottayam for their valuable guidance, motivation and help during this study.

\section{REFERENCES}

[1] Ummerali KS, Sarojini S. Correlation of HER2/neu expression and histopathological grading and staging of colorectal carcinomas. Journal of Evolution of Medical and Dental Sciences 2017;6(60):4407-11.

[2] Jemal A, Murray T, Ward E, et al. Cancer statistics, 2005. CA Cancer J Clin 2005;55(1):10-30.
[3] Lee WS, Kang M, Baek JH, et al. Clinical impact of tumor-infiltrating lymphocytes for survival in curatively resected stage IV colon cancer with isolated liver or lung metastasis. Annals of Surgical Oncology 2013;20(2):697-702.

[4] English DP, Roque DM, Santin AD. HER2 expression beyond breast cancer: therapeutic implications for gynecologic malignancies. Molecular Diagnosis \& Therapy 2013;17(2):85-99.

[5] Shabbir A, Mirza T, Khalid AB, et al. Frequency of HER2/neu expression in colorectal adenocarcinoma: a study from developing South Asian country. BMC Cancer 2016;16(1):855.

[6] Seo AN, Kwak Y, Kim DW, et al. HER2 status in colorectal cancer: its clinical significance and the relationship between HER2 gene amplification and expression. PLoS One 2014;9(5):e98528.

[7] Suma S, Ummarali SK. HER2/neu expression in colorectal cancers. International Journal of Contemporary Medical Research 2017;4(6):1240-3. 